\title{
Technical Note \\ Satellite Survey of Offshore Oil Seep Sites in the Caspian Sea
}

\author{
Marina Mityagina * ${ }^{(D)}$ and Olga Lavrova \\ Space Research Institute of Russian Academy of Sciences, 117997 Moscow, Russia; olavrova@iki.rssi.ru \\ * Correspondence: mityag@iki.rssi.ru
}

\begin{abstract}
This paper presents the results of a long-term survey of the Caspian Sea using satellite SAR and multispectral sensors. The primary environmental problem of the Caspian Sea is oil pollution which is determined by its natural properties, mainly by the presence of big oil and gas deposits beneath the seabed. Our research focuses on natural oil slicks (NOS), i.e., oil showings on the sea surface due to natural hydrocarbon emission from seabed seeps. The spatial and temporal variability of NOS in the Caspian Sea and the possibilities of their reliable detection using satellite data are examined. NOS frequency and detectability in satellite images depending on sensor type, season and geographical region are assessed. It is shown that both parameters vary significantly, and largely depend on sensor type and season, with season being most pronounced in visible (VIS) data. The locations of two offshore seep sites at the Iranian and Turkmenian shelves are accurately estimated. Statistics on individual sizes of NOS are drawn. The release rates of crude oil from the seabed to the sea surface are compared. Detailed maps of NOS are put together, and areas exposed to high risk of sea surface oil pollution are determined.
\end{abstract}

Keywords: satellite remote sensing; radar imagery; multispectral data; sea surface; surface films; natural oil slicks; oil pollution; the Caspian Sea; natural hydrocarbon seeps; satellite monitoring

check for

updates

Citation: Mityagina, M.; Lavrova, O. Satellite Survey of Offshore Oil Seep Sites in the Caspian Sea. Remote Sens. 2022, 14, 525. https://doi.org/ $10.3390 /$ rs 14030525

Academic Editor: Merv Fingas

Received: 20 December 2021

Accepted: 19 January 2022

Published: 22 January 2022

Publisher's Note: MDPI stays neutral with regard to jurisdictional claims in published maps and institutional affiliations.

Copyright: (c) 2022 by the authors. Licensee MDPI, Basel, Switzerland. This article is an open access article distributed under the terms and conditions of the Creative Commons Attribution (CC BY) license (https:// creativecommons.org/licenses/by/ $4.0 /)$.

\section{Introduction}

Today the study of the World Ocean is impossible without the use of satellite remote sensing data. Many satellites with scientific instruments on board, operating in different electromagnetic spectrum ranges, have been launched worldwide. Data accuracy and resolution of satellite sensors are constantly growing. Environmental research technologies based on satellite remote sensing of the Earth are being actively developed and applied to various natural objects, including the marine environment. The primary type of contamination in the focus of sea surface satellite studies is oil-containing films. Many works are devoted to developing satellite techniques of sea surface oil pollution control [1-7].

High levels of marine environment pollution result from anthropogenic and natural sources. Natural hydrocarbon seabed seeps attract substantial attention from researchers. These are natural leaks of liquid and gaseous hydrocarbons fed by underground oil and gas deposits. Natural hydrocarbon seabed seeps are geographically widespread and release oil from deep sources to the surface over long geological periods. According to some estimates [8], currently, 53\% of the crude oil entering the oceans is the result of leaks and spills during the extraction, transportation, processing, storage, and industrial use of oil and from accidents on oil drilling platforms and ships.

In comparison, $47 \%$ is due to natural seeps from the seabed. The interest for determining the regions of natural hydrocarbon seabed seeps, the reasons why they occur and developing methods of their regular survey is growing worldwide. It is commonly noticed that their surface indications characterize all major petroleum provinces, whereas the converse is not necessarily true [9].

Faults or fractures in the seabed provide natural fluid pathways through which gas bubbles, sometimes coated with oil, are released into the water column. While most of these dissolve in the water column, a certain amount reaches the surface. There, the gas 
is released into the atmosphere. The oil remaining on the sea surface forms a thin layer on it [10]. This thin layer of oil floating on the surface suppresses surface roughness and forms an oil slick. Various amounts of oil regularly appear on the sea surface over the seeps. Below, such oil showings on the sea surface due to natural hydrocarbon emission from seabed seeps will be referred to as natural oil slicks (NOS).

The traditional contact and visual methods of exploring natural hydrocarbon seeps on the seabed provide limited opportunities. The data obtained from such studies are often patchy. Meanwhile, satellite remote sensing techniques allow regular observations in large areas with high spatial resolution and provide excellent opportunities for investigating and mapping NOS, both on the shelf and in the deep-water zones. Satellite remote sensing allows observation of the NOS drift and spreading over the sea surface under the combined effect of wind and surface currents [11].

Many scientific publications have appeared to date, focusing on satellite observations of NOS. These phenomena have been found and studied in various regions worldwide [12-17], and the flow of such works does not seem to run out.

There are many regions of particular interest for researchers. First of all, they include the Gulf of Mexico, where NOS have been observed and studied since the dawn of remote sensing [18-25].

Furthermore, considerable attention is drawn to the continental shelf along the northern margin of the Santa Barbara Channel, abundant in natural hydrocarbon seeps [26-28].

Many studies have been done on NOS on the sea surface over the continental slope in the southwestern Black Sea [29-33].

Unfortunately, publications based on satellite observations of oil pollution due to seabed seeps in the Caspian Sea are relatively scarce. They mainly discuss results of satellite observations in the Oil Rocks oil production area in the Middle Caspian [34,35]. Furthermore, one research paper [36] presents satellite observations of NOS in the southwestern part of the Caspian Sea, which belongs to Iran. Another work [34] analyzes oil spills and NOS's spatial and temporal patterns in the Caspian Sea. Such a modest amount of published results could be explained by the fact that none of the Caspian countries, except Russia, conduct satellite monitoring of the aquatic area of the sea.

Our team has carried out satellite surveys of the Caspian Sea for a long time. Our earlier studies outlined the main types of oil pollution typical of different sea parts and revealed its main patterns [37-39]. Our previously published results demonstrate a longoverdue need to implement operational satellite monitoring of the Caspian Sea surface pollution to reveal the sources of pollution, quantitatively assess its scale, and predict drift and spreading parameters.

The main objective of this work is to enhance the reliability of detecting NOS using satellite data. The research presented in this article is novel and important in various aspects. The essential point in the reported studies is an attempt to identify the limitations of remote sensing methods for detecting NOS. Remote sensing is undoubtedly the best method for detecting oil spills, including NOS. Still, it also has its limitations, not only arising from the physical nature of the signal formation of various sensors but also due to the natural conditions at the time of observation. Knowledge of these limitations should enhance the reliability of detecting NOS and obtaining their quantitative estimates using satellite data.

Next, despite the worldwide interest in the remote study of NOS in different regions of the World Ocean, no such research has been carried out in the Caspian Sea before. Considering that the Caspian washes the coasts of five countries, the problem of transboundary oil transfer may arise. In this case, understanding the source of oil pollution-anthropogenic or natural-is an important task.

Moreover, the studies of oil pollution so far are mainly based only on SAR data. As we demonstrate below, VIS data can also contribute to a comprehensive description of the state of pollution. 
Achieving the study's goals required availability and further detailed analysis of an extensive dataset of satellite data. Note that the very formulation of the problem became possible only with the appearance of a continuous flow of high spatial resolution data obtained in different ranges of the electromagnetic spectrum by satellite sensors of the European Space Agency's Sentinel family. They provide previously unattainable spatial resolution and repeatability of surveys. Efficient work with these datasets was ensured by the powerful capabilities of a satellite information system employing technologies of automatic management of continuously renewed archives of satellite data and versatile analysis tools, described in short in Section 3.

In the paper, we will:

- focus on applications of satellite remote sensing, by both SAR and multispectral instruments, in the detection and analysis of spatiotemporal characteristics of NOS in the shelf zones of the Caspian Sea.

- examine NOS frequency and detectability in satellite imagery of two regions of interest;

- analyze the seasonal and annual variability of individual sizes of NOS detected in satellite images taken over the regions of interest and discuss its possible causes;

- $\quad$ assess the probability of contamination of the sea surface in the vicinity of natural seabed hydrocarbon seeps.

The remainder of this paper is organized as follows: In Section 2, we outline the regions of interest and briefly describe their particular natural properties most relevant to the performed research. In Section 3, we introduce the SAR and VIS data used in this study and detail the means and techniques of their analysis. Here, we also discuss the benefits and drawbacks of various data types for NOS detection and present examples of NOS signatures in satellite images obtained by different sensors. The experimental results and comparative analysis are given in Section 4 . In Section 5 , the seasonal variability in NOS frequency and detectability in SAR and VIS images and its possible reasons are discussed. The limitations of the remote sensing methods for detecting oil slicks on the sea surface and their possible reasons are described. Finally, the conclusions are presented in Section 6.

\section{Study Regions}

The Caspian Sea is located at the junction of the two parts of the Eurasian continentEurope and Asia. Five countries surround this sea: Russia, Azerbaijan, Iran, Turkmenistan, and Kazakhstan. This is the largest enclosed body of water on Earth, and in terms of size, the Caspian Sea exceeds such lakes as Upper, Victoria, Huron, Michigan, and Baikal. According to formal signs, the Caspian Sea is a closed lake. Nevertheless, considering its large size, salty water, and a regime similar to the sea, this body of water is called a sea.

The average depth of the Caspian Sea is $208 \mathrm{~m}$, and the maximum depth is $1025 \mathrm{~m}$. There are no tides in this sea. The main factors determining water circulation are wind, bottom topography, a configuration of the coastline, differences in the temperature of waters in different parts of the sea, and the flow of rivers. On average, the depth of the sea shelf is less than $100 \mathrm{~m}$. At the western coast, the shelf is narrow, with an average width of $40 \mathrm{~km}$. At the eastern coast, the shelf is more extensive, with an average width of about $130 \mathrm{~km}[40]$.

The Caspian Sea features large oil and gas deposits beneath its bottom that, in many respects, determine the distribution and shape of surface oil pollution observed by satellite sensors. The primary pollution sources are exploration and exploitation of oil deposits and natural oil seeps at the sea bottom. According to some estimates [41], about one million tons of oil a year comes to the Caspian Sea from various sources.

Two regions attracted our attention because of slick patterns remarkably different in structure from ship spills, widespread slicks of biological origin and vast slicks around the Oil Rocks area that were regularly observed in satellite images. The principal feature of these unusual slicks is their fixed link to specific geographical locations. We detected many slicks attached to specific active emission points in both regions. The recurrence of slicks in 
the same place is the main criterion for their attribution to NOS [37]. These two Caspian regions of interest marked by red rectangles in Figure 1 are located:

(1) east of Cape Sefid Rud (Iran);

(2) west of the Cheleken Peninsula (Turkmenistan).

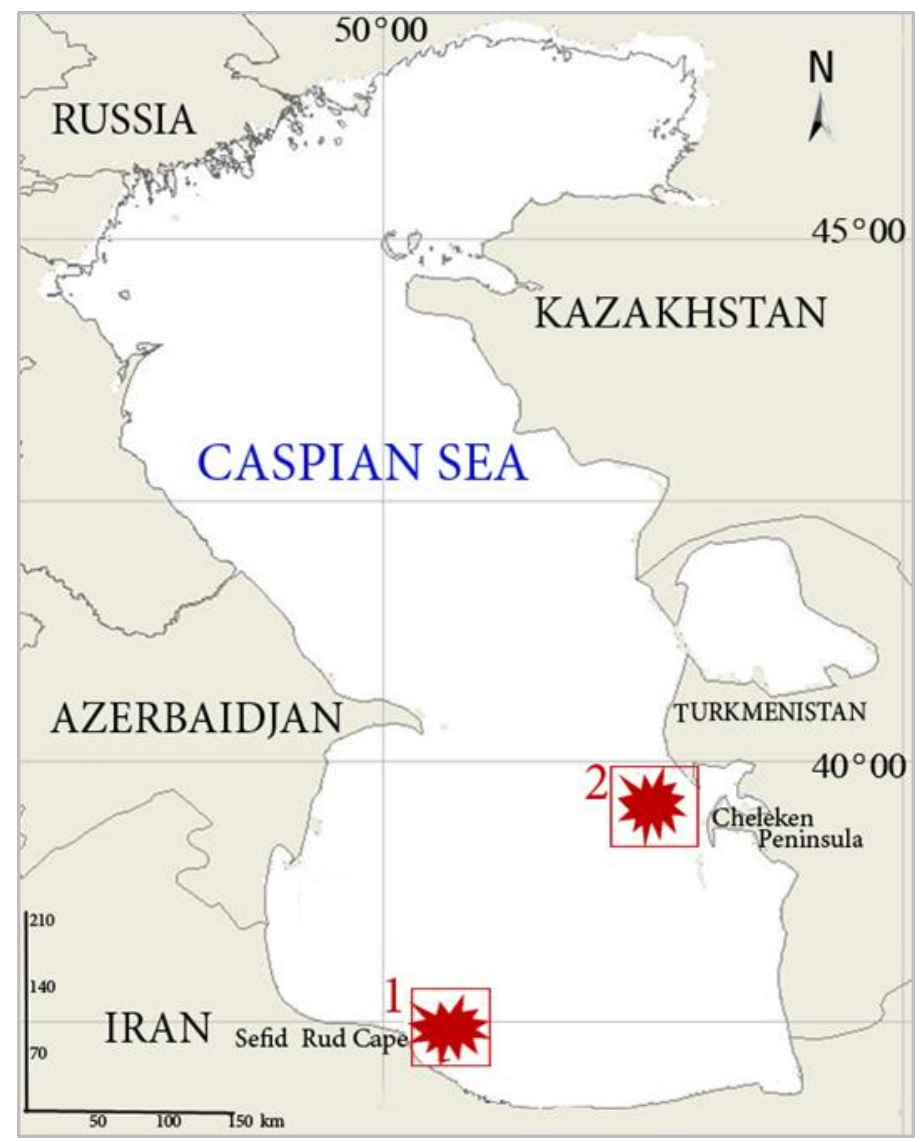

Figure 1. Regions of interest are natural hydrocarbon seabed seep sites: 1-east of Cape Sefid Rud; 2-west of Cheleken Peninsula.

\section{Data and Methods}

\subsection{Data and Data Processing}

This study examined all Envisat ASAR images of the Caspian Sea obtained over the two regions of interest from January 2010 to January 2012 and Sentinel-1 SAR images taken from January 2015 to December 2020. Visible (VIS) data with less than 10\% cloud cover for these periods were also analyzed (see Tables 1 and 2).

Table 1. Analyzed satellite data for the region of Cape Sefid Rud.

\begin{tabular}{ccc}
\hline Sensor & Period & Number of Images \\
\hline ASAR Envisat & January 2010-January 2011 & 39 \\
SAR-C Sentinel-1A, -1B & January 2015-December 2020 & 413 \\
TM Landsat-5 & January 2010-August 2011 & 17 \\
MSI Sentinel-2A,-2B & July 2015-December 2020 & 154 \\
OLI Landsat-8 & February 2014-December 2020 & 71 \\
\hline
\end{tabular}


Table 2. Analyzed satellite data for the region of Cheleken Peninsula.

\begin{tabular}{ccc}
\hline Sensor & Period & Number of Images \\
\hline ASAR Envisat & January 2010-March 2012 & 77 \\
SAR-C Sentinel-1A,-1B & January 2015-December 2020 & 459 \\
TM Landsat-5 & January 2010-August 2011 & 28 \\
MSI Sentinel-2A,-2B & July 2015-December 2020 & 129 \\
OLI Landsat-8 & February 2014-December 2020 & 108 \\
\hline
\end{tabular}

In total, we examined 702 satellite images of the Caspian Sea obtained over the Iranian waters and 801 satellite images over the Turkmenian waters. Figure 2 depicts diagrams showing the distribution of all analyzed images, SAR (blue bars) and VIS (orange bars), as well as the total number of NOS detected (grey lines) in the two regions of interest by year.

The data gap in 2012-2014 is explained by the end of the Envisat operation when Sentinel was not yet in orbit. There was no SAR data amount sufficient to draw any reliable statistics in this period.

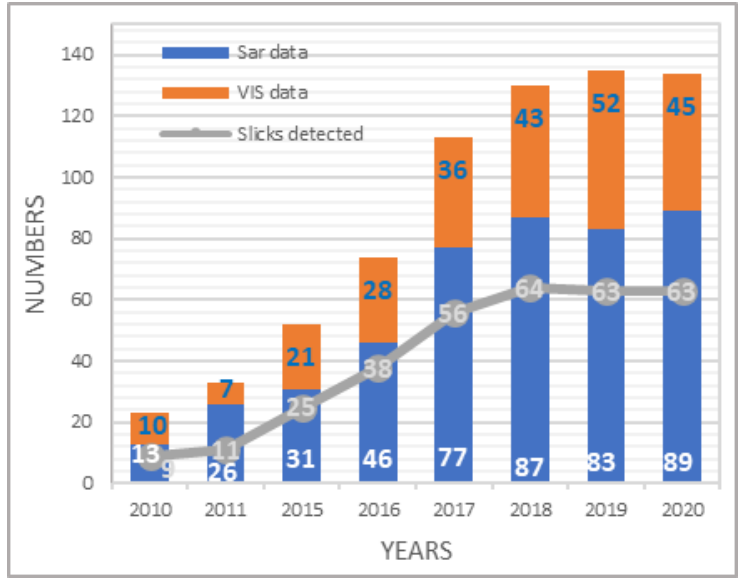

(a)



(b)

Figure 2. Inter-annual distribution of satellite data analyzed, and NOS detected: (a) in the Cape Sefid Rud region; (b) in the Cheleken Peninsula region.

The satellite data were processed and analyzed using the toolkit of the See the Sea (STS) satellite information system developed at the Space Research Institute of the Russian Academy of Sciences (IKI RAS). STS functionality is described in [42]. STS provides instruments for fast and easy access to satellite data and products and various tools for specialized data analysis. STS enables easy search in a distributed image archive using sensor type, time period, and location as search criteria.

An image selected for further analysis is visualized in the map area of the interface, along with its geographic basis and related cartographic data. All information (regardless of sensor type or product) is displayed in the same cartographic projection for a given geographic area, facilitating data selection for analysis. The main characteristics of NOS were determined using the STS interface in an interactive semi-automatic mode. As a result, we have a particularized description of the phenomena stored in the database.

The database provides capabilities to:

- $\quad$ store and visualize graphical and attributive information;

- $\quad$ perform hierarchical classification of observed processes;

- $\quad$ search for data by spatial, time and typological criteria;

- map oil pollution of different types.

We used an STS classification tool to detect structures assuredly belonging to oil slicks in satellite images. This tool allows dividing satellite images into separate classes according 
to preset parameters. We used signature calculation and maximum likelihood classification to highlight oil slick features. The method is based on automatic clustering by spectral (for VIS data) or brightness (for SAR data) likelihood criterion. The implemented classification algorithms were taken from the GRASS GIS modules detailed in [43]. We then considered only slicks with fixed links to particular geographical locations. They were classified as NOS and affixed into the cartographic interface for further analysis.

\subsection{NOS in Satellite Images}

SAR is an appropriate tool for surface pollution monitoring because of its high resolution and insusceptibility to cloud and sunlight conditions. A SAR survey of oil pollution of the sea surface is based on the capability of satellite radar imagery to reveal sea surface areas covered by surface films. Surface films cause a reduced interaction of ocean waves and wind and an attenuation of the resonance gravity-capillary component of surface waves. This is how smooth areas, i.e., slicks, appear on the sea surface that are translated into signatures of reduced backscatter in radar images. SAR has been used to detect the presence of oil on the sea surface for many years $[44,45]$.

Data taken by satellite sensors in VIS bands of the electromagnetic spectrum provide significant value for marine observation systems. VIS data can help resolve ambiguities in interpreting SAR data and detecting oil slicks on the sea surface. A limitation of this data is due to solar illumination and weather conditions, as a cloud cover may prevent radiance penetration. Sea surface state, area illumination, and viewing direction affect reflected brightness. In VIS images, oil films appear due to two factors: (i) differences in the reflection coefficients of a clean sea surface and the water-film system; (ii) changes in the geometry of the sea surface caused by excellent elastic properties of such films. Oil films in VIS images, especially in images obtained in sun glint zones, may be visible even better than in SAR images. Sun glint refers to a reflection of solar radiation from the sea surface observed by optical sensors when the sunlight incidence angle is equal to the reflection angle. The presence of inhomogeneous roughness, i.e., surface waves, gives rise to a set of small tilted facets reflecting sunlight at a variety of different angles and directions. The size and shape of the sun glint pattern depend on the probability distribution of the slopes of the facets caused by the sea surface roughness, the direction of the incident sunlight, and the sensor viewing angle [46]. Thus, differences in the sea surface roughness variance in the sun glint region manifest themselves as variations in the image brightness. In the sun glint region, areas covered by films appear brighter because the surface film reduces the sea surface roughness. More local elements are present, reflecting light to the sensor. The opposite situation occurs outside the sun glint zone: lower reflected brightness corresponds to more minor surface roughness due to fewer local slopes reflecting solar radiation in the viewing direction.

NOS are easily recognizable in satellite images. As a rule, oil leaks from a vent or a group of vents on the seabed and reaches the surface not far from the underlying source point on the seabed. We can say that a persistent occurrence of slicks emanating from a stable emission point serves as an indicator of a natural seabed seep.

Figures $3 a-c$ and $4 a-c$ show SAR signatures of NOS typical of the continental slope near Cape Sefid Rud and Cheleken Peninsula, respectively. In SAR images, NOS are seen as dark bands of reduced backscatter.

Figures $3 \mathrm{~d}-\mathrm{f}$ and $4 \mathrm{~d}-\mathrm{f}$ show colour composites derived from VIS data taken in a sun glint area. Here, NOS have increased brightness and appear as bright structures. We see bright bands surrounded by a dark halo that broadens with film spreading.

Sea currents exhibit dynamic multi-directional patterns and speed, which explain spatial variations of oil slicks depicted in Figures 3 and 4. In the area of the Iranian shelf, current direction and velocity are influenced more by coastline configurations, bottom morphology, and Coriolis force than by wind. Current velocity values are inconsistent, directions are mainly southeastward $\left(120-180^{\circ}\right)$. The maximum current velocities are associated with these directions. The current field is more complicated at the eastern coast 
than at the western coast, which is connected with a clearly pronounced seasonal variability of the prevailing winds. Besides, currents in this part of the sea are influenced by a strongly indented coastline with numerous capes, bays and gulfs [40].

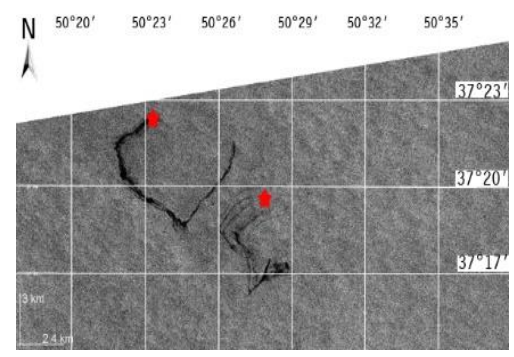

(a)

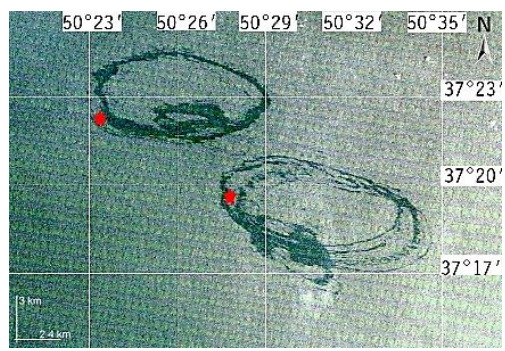

(d)

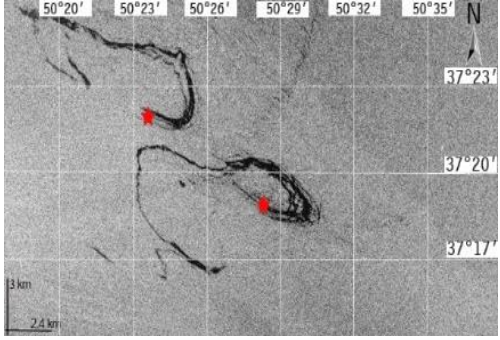

(b)

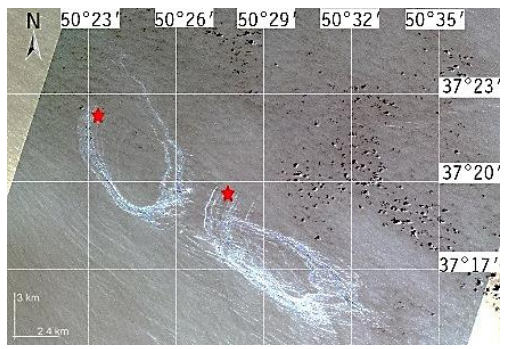

(e)



(c)

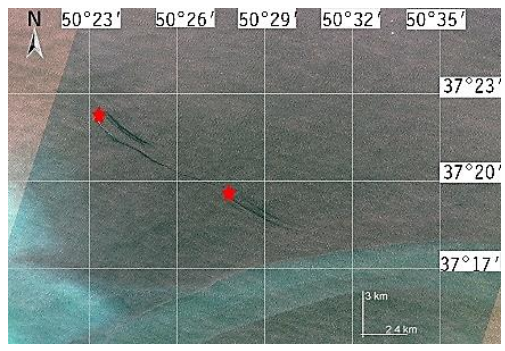

$(\mathbf{f})$

Figure 3. Examples of NOS in the Cape Sefid Rud region in the satellite data: (a) Sentinel-1A SAR-C of 16 February 2015, 14:36 UTC; (b) Sentinel-1A SAR-C of 25 June 2018, 02:36 UTC; (c) Sentinel-1A SAR-C of 9 December 2018, 14:36 UTC; (d) Landsat-5 TM (color composites of bands 3, 2 and 1) of 11 June 2010, 07:04 UTC; (e) Sentinel-2A MSI (color composites of bands 4, 3 and 2) of 30 June 2018, 07:38 UTC; (f) Sentinel-2A MSI (color composites of bands 4, 3 and 2) of 3 September 2019, 07:38 UTC.

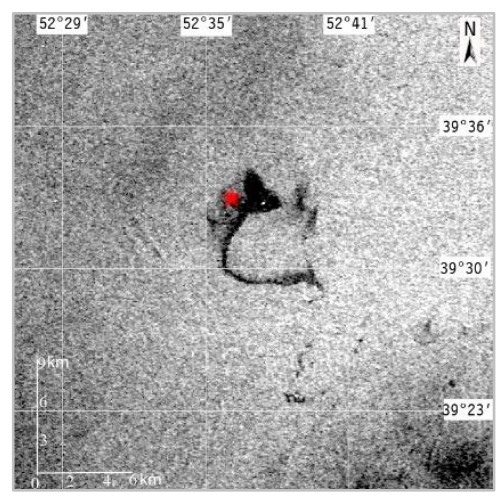

(a)



(b)

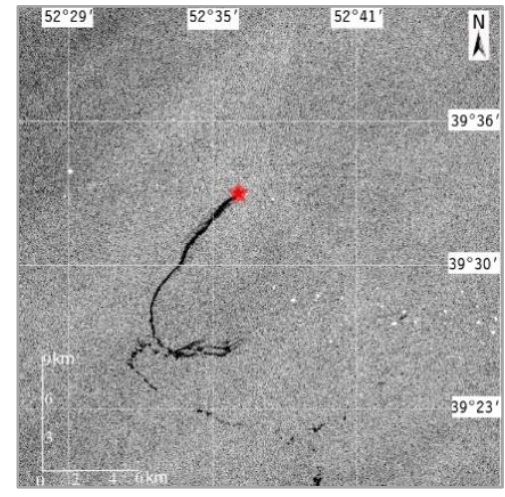

(c)

Figure 4. Cont. 


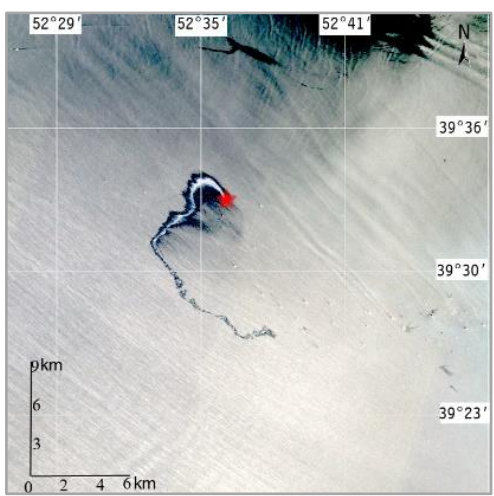

(d)

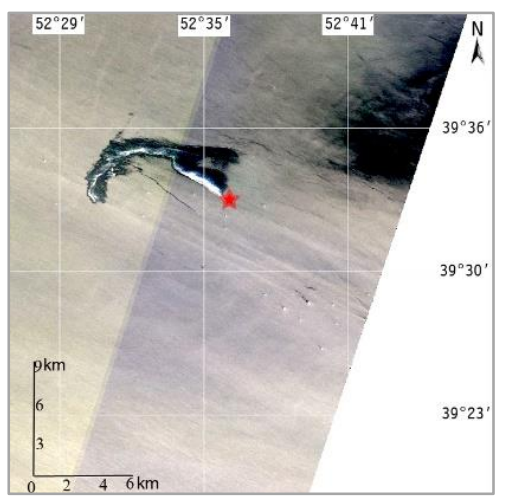

(e)

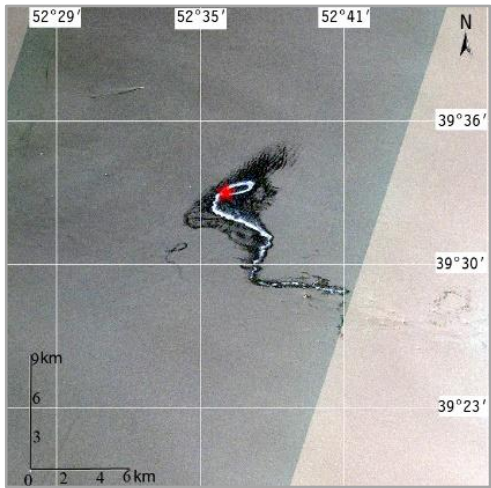

(f)

Figure 4. Examples of NOS in the Cheleken Peninsula region in the satellite data: (a) Envisat ASAR of 27 June 2010, 06:42 UTC; (b) Sentinel-1A SAR-C of 25 July 2018, 14:28 UTC; (c) Sentinel-1A SAR-C of 8 June 2019, 02:36 UTC; (d) Landsat-8 OLI (color composites of bands 4, 2 and 1) of 15 June 2014, 07:07 UTC; (e) Landsat-8 OLI (color composites of bands 4, 2 and 1) of 14 August 2016, 07:13 UTC; (f) Sentinel-2A MSI (color composites of bands 4, 3 and 2) of 18 May 2018, 07:28 UTC.

The slick bands shaped as ellipses or semicircles (Figure 3b,d,e) are of interest. Such shapes are most probably the effect of near-inertial oscillation (NIO). They are a specific characteristic of NOS when oil is released slowly and over time from a fixed location on the seabed. NIO occurs under an external influence, most often a wind pulse. After a reduction of the external impact, NIO is established, and no more external force is required to maintain it [24].

In the Cheleken Peninsula region, the seep site is located in an oil-producing area and is surrounded by oil-drilling platforms seen in the satellite data as bright dots. Nonetheless, the identified source of oil slicks is a natural seep on the sea bottom tied to an oil-bearing structure. However, it is possible that active oil production in the area can affect the frequency and intensity of oil emission from the seabed source. Over the past years, daily oil production in the Cheleken area increased from about 7000 barrels per day up to 100,000 barrels per day. More than 100 new wells have been drilled here.

Analyzing the slicks locations in the satellite images taken in the Cape Sefid Rud region, we associated the slick patterns with two closely located vents. Two or more distinct slick bands can be observed at both emersion points because the seep vents have more than one channel through which oil migrates from the seabed to the surface. The southern vent appears to be less intensive than the northern one because the releases are less frequent and lower in volume. Moreover, most images taken in the Cape Sefid Rud region feature oil slicks with a striped pattern because oil from the vents is brought to the sea surface by oily bubbles rising from several gas plumes. In the course of evolution and spreading, the stripes can merge in one or, though mostly behaving in sync, remain separated.

\section{Results}

\subsection{NOS Frequency and Detectability in Satellite Images}

We started the investigation by revealing the seasonal variations in the frequency of NOS identified in the satellite images taken by various sensors over the regions of interest (NOS frequency). Here, by NOS frequency, we understand the number of NOS detected during a given period of time in a year in percentage to the total number of NOS detected in this year.

Figure 5 shows the monthly distribution of NOS frequency in SAR (blue bars) and VIS (orange bars) images. The grey lines show the monthly distribution of the overall number of NOS detected in the satellite data, both SAR and VIS. 




(a)

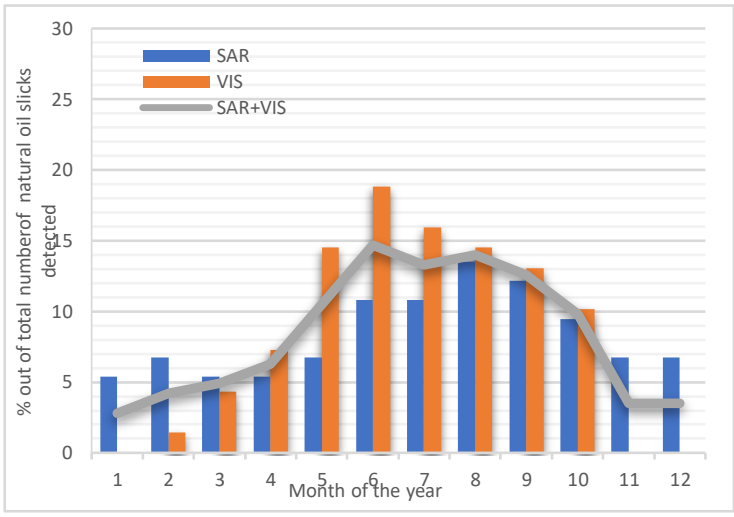

(b)

Figure 5. Monthly variability of NOS frequency in SAR and VIS images: (a) of the Cape Sefid Rud region; (b) of the Cheleken Peninsula region.

Noteworthy is the pronounced seasonal variability in NOS frequency for VIS images. Near the Cape Sefid Rud, the vast majority of NOS, about $85 \%$, were identified in VIS images during the warm season, from May to August. None were detected from December to March over the whole study period. In contrast, in SAR images, NOS were also identified in winter. We got similar results for the Cheleken Peninsula region. However, here, the seasonal distribution is smoother. Seasonal variability in NOS frequency also exists in SAR images but is much less pronounced.

Further, we concentrated on the share of SAR or VIS images with NOS signatures among all images. For a given period of time, by NOS detectability, we understand the number of satellite images bearing distinct signatures of NOS in the percentage of the total number of obtained satellite images. Figure 6 presents the inter-annual distribution of NOS detectability.

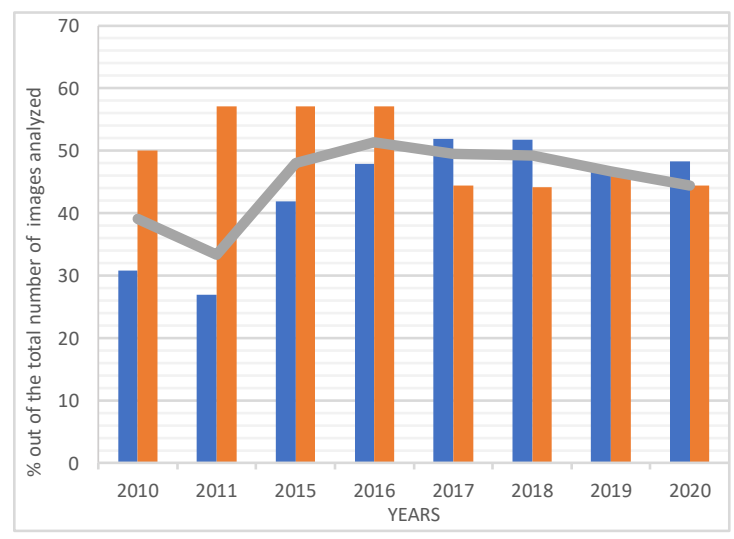

(a)

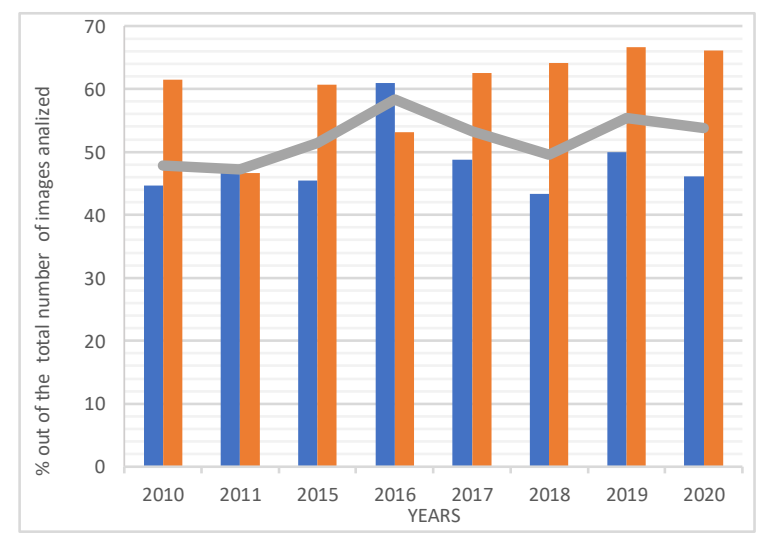

(b)

Figure 6. Inter-annual variability of NOS detectability near: (a) the Cape Sefid Rud; (b) the Cheleken Peninsula. SAR - blue bars, VIS — orange bars. Grey lines show the overall percentage of SAR and VIS images bearing distinct NOS signatures.

We found that during the whole study period, NOS detectability in satellite images (both SAR and VIS) of the Cape Sefid Rud region varied within 33-50\%. NOS structures were identified in $47-60 \%$ of images taken in the Cheleken Peninsula region in the same period.

Meanwhile, average monthly NOS detectability is much more variable over the year, especially for the VIS data (see Figure 7). 


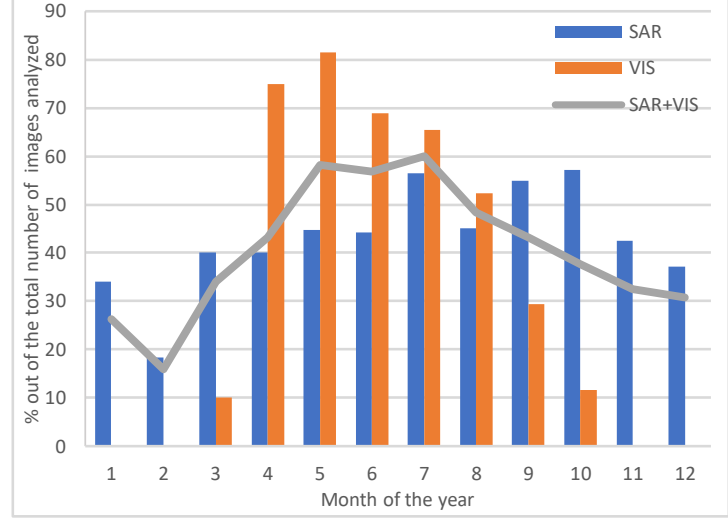

(a)

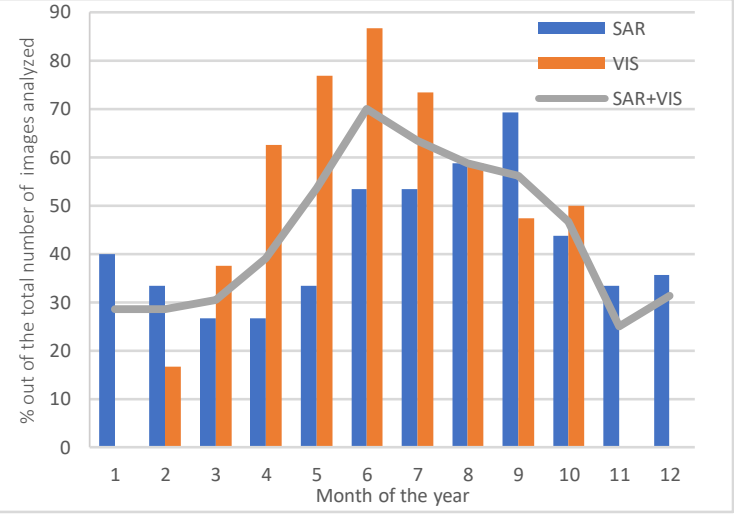

(b)

Figure 7. The monthly distribution of NOS detectability averaged over the whole study period near: (a) the Cape Sefid Rud; (b) the Cheleken Peninsula.

\subsection{Individual NOS Sizes}

The distributions of individual sizes of NOS detected in the satellite images taken over the two seep sites are shown in Figure 8. It should be stressed that these estimates are derived solely from satellite imagery, whereas actual areas measured in situ can differ depending on local wind/wave conditions.

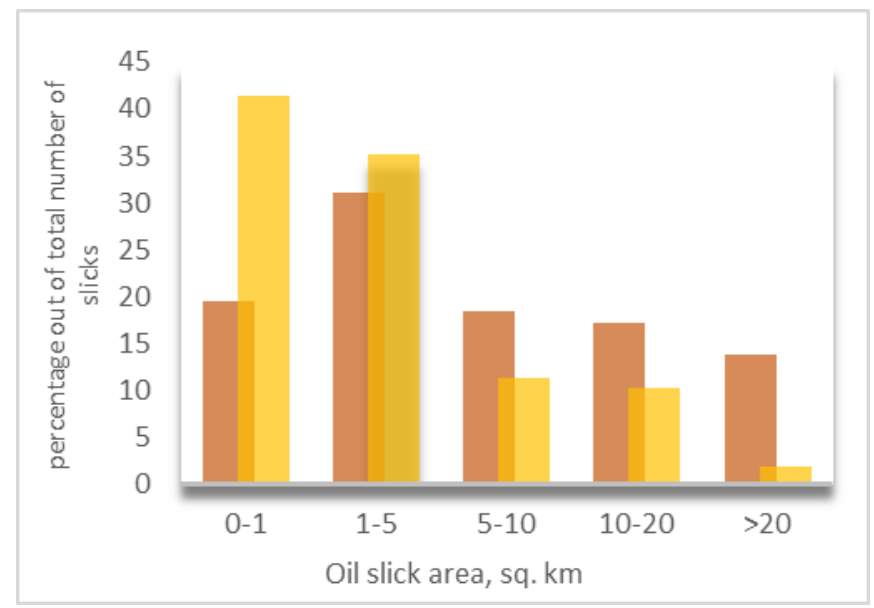

Figure 8. Distribution of individual sizes of NOS detected in the satellite images of the Cape Sefid Rud (brown bars) and Cheleken Peninsula (yellow bars) regions.

Individual sizes of NOS detected in different years (Figure 8) range from 0.01 to $45 \mathrm{~km}^{2}$ for the Cape Sefid Rud region and from 0.01 to $75 \mathrm{~km}^{2}$ for the Cheleken Peninsula region. More than $75 \%$ of NOS detected in the Cape Sefid Rud region are less than $5 \mathrm{~km}^{2}$ in size and $40 \%$ less than $1 \mathrm{~km}^{2}$. In the Cheleken Peninsula region, more than half of NOS are over $5 \mathrm{~km}^{2}$, and more than $25 \%$ exceed $10 \mathrm{~km}^{2}$.

On the whole, near the Iranian coast, NOS have smaller dimensions than near the Turkmenian coast. Thus, we can state that the release rates of crude oil from the seabed to the surface are higher in the Turkmenian waters.

\subsection{Maps of Sea Surface Oil Pollution}

The mapping schematics of NOS extracted from the satellite data for the Cape Sefid Rud and the Cheleken Peninsula regions are shown in Figure 9a,b. A large amount of available satellite data allowed us to locate the seep sources accurately.

In the case of the Iranian shelf, two hydrocarbon seeps located close to each other on the sea bottom are documented as persistent sources of 157 and 172 NOS with coordinates 
$50^{\circ} 24.4^{\prime} \mathrm{E}, 37^{\circ} 23.4^{\prime} \mathrm{N}$, and $50^{\circ} 28.9^{\prime} \mathrm{E}, 37^{\circ} 20.4^{\prime} \mathrm{N}$, respectively. The seabed seep near the Cheleken Peninsula is documented as a persistent origin of 423 NOS detected in the satellite images. Their "source" point coordinates determined as $52^{\circ} 36.2^{\prime} \mathrm{E}, 39^{\circ} 32.9^{\prime} \mathrm{N}$ evidently indicate the seabed hydrocarbon seep location. The seep is situated on the continental shelf at a depth of approximately $25 \mathrm{~m}$ and at a distance of $44 \mathrm{~km}$ from the western end of Cheleken Peninsula. This seep was not previously mentioned in the scientific literature or in maps. We discovered it during our study reported in [38].

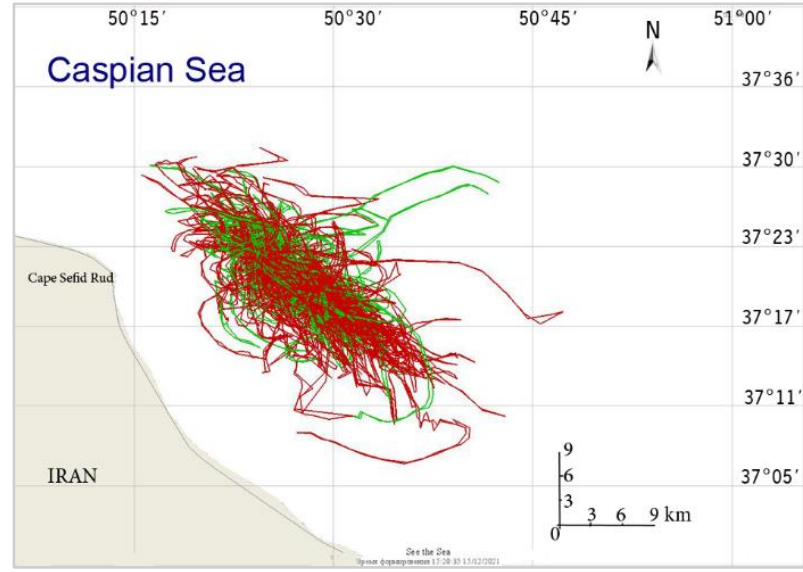

(a)

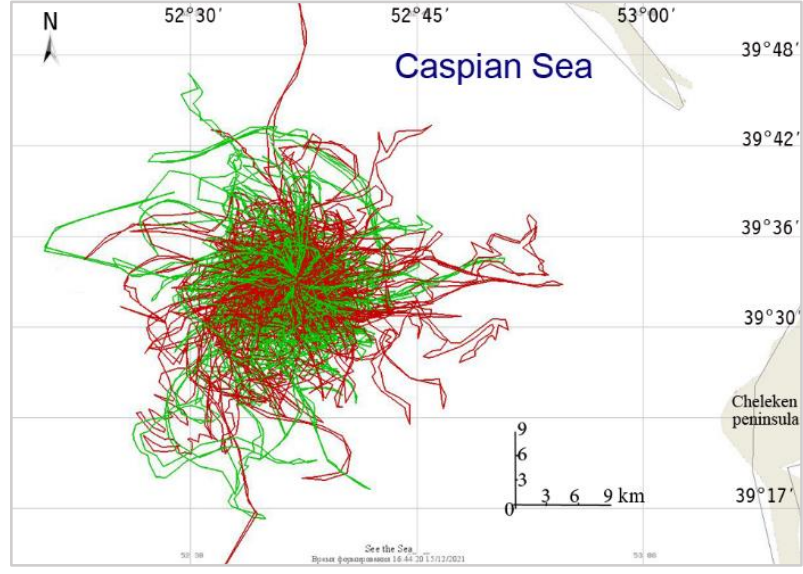

(b)

Figure 9. Consolidated maps of NOS from seabed seeps revealed in the satellite images: (a) of the Cape Sefid Rud region; (b) the Cheleken Peninsula region.

After reaching the surface, NOS form, as a rule, thin curved stripes and can spread over long distances-up to $35 \mathrm{~km}$ in the Cape Sefid Rud region and up to $50 \mathrm{~km}$ in the Cheleken Peninsula region. This significantly increases the sea surface area potentially prone to oil pollution, despite the relatively small area of each individual slick. As a result, more than $1200 \mathrm{~km}^{2}$ of the sea surface in the Cape Sefid Rud region and more than $1500 \mathrm{~km}^{2}$ in the Cheleken Peninsula region are potentially exposed to oil pollution. A high risk of sea surface oil pollution from natural seabed seeps is attributed to areas of $100 \mathrm{~km}^{2}$ and $200 \mathrm{~km}^{2}$ correspondingly.

\section{Discussion}

The majority of published results of satellite observations of NOS at the sea surface are based on SAR data. Our research uses SAR and VIS data and examines their capabilities to detect NOS reliably.

The major fact that demands consideration is the striking seasonal variability in NOS frequency and detectability demonstrated by VIS and SAR images. We believe that it is not related to variations in the rate of hydrocarbon emission from the seeps. Other factors significantly affect the reliable detection of NOS in satellite data:

Cloud cover and solar illumination are big problems and limitations for VIS data, whereas SAR can detect oil slicks day and night through clouds and is insusceptible to solar light conditions. For VIS data, illumination and cloud limitation are the main reason for the revealed seasonal variability in NOS detectability. It should be emphasized again that in our study we analyzed all available SAR data and only those VIS data where cloud cover did not exceed 10\%. The percentage of such VIS data varies significantly throughout the year. Therefore, the seasonal variability in NOS detectability in VIS data is primarily due to the variability in the amount of data suitable for analysis. There are more data in the warm season and less in the cold one.

The seasonal variability in NOS frequency and detectability in SAR images is much smoother. This fact can be explained by a different mechanism of oil slicks manifestation in SAR images. SAR can detect oil slicks through clouds and independently of sunlight. 
The atmosphere is transparent for the radar signal at all times. The detectability of oil slicks in SAR images depends mainly on wind and the ocean-atmosphere boundary layer conditions at the survey time.

The near-surface wind is the most critical factor affecting the reliable detection of sea surface oil slicks in SAR images. This fact was first established at the end of the past century in a series of controlled slick experiments where various quasi-biogenic substances and mineral oils were deployed on the sea surface within the swath of satellite SARs [47]. The results of the experiments were confirmed both analytically and by SAR observations over the following years.

Wind speeds from 3 to $10 \mathrm{~m} / \mathrm{s}$ were specified as a preferable condition for oil slick detection in satellite SAR images [48,49]. A NOS signature is clearly seen in a SAR image (Figure 10a) taken over the continental slope in the Cape Sefid Rud area under a favourable wind speed of $6 \mathrm{~m} / \mathrm{s}$.

It is practically impossible to identify oil slicks under high winds (stronger than $10 \mathrm{~m} / \mathrm{s}$ ) that often occur during the cold season. A radar image taken under wind speeds of $11 \mathrm{~m} / \mathrm{s}$ is shown in Figure 10b. The mixing of oil with seawater can be greater during the cold season. A combination of strong wind and waves inhibits the formation of a NOS. In such cases, a minimal dark area of decreased radar backscatter can be detected near the emission point. The mixing of oil with seawater could be greater during the cold season. Waves $2 \mathrm{~m}$ high predominate near the southwestern coasts during strong winds $(10-15 \mathrm{~m} / \mathrm{s})$. When the wind gets stronger up to $20 \mathrm{~m} / \mathrm{s}$, wave height increases up to $3 \mathrm{~m}$ and, in case of a strong storm $(25 \mathrm{~m} / \mathrm{s})$, reaches $4 \mathrm{~m}$ and more. At the Turkmenian coast, storm winds $(16-20 \mathrm{~m} / \mathrm{s})$ induce waves up to $3 \mathrm{~m}$ high and robust storms $(21-25 \mathrm{~m} / \mathrm{s})$ up to $4 \mathrm{~m}$ high [40].

On the other hand, many low-backscatter areas unrelated to oil films can be seen in SAR images obtained under the weak near-surface wind. The capillary-gravity component of the sea surface wave field may not develop under weak-to-no-wind conditions. Hence large dark zones of low backscatter appear in SAR images. These low scattering (dark) areas in radar images increase the "false alarm" probability. NOS located in these zones are hardly detectable. Figure 10c illustrates this situation.

Some atmospheric processes become visible in SAR images due to the inhomogeneities they induce on the gravity-capillary component of the sea surface wave field. Wind field variations modulate short gravity waves at the sea surface resulting in inhomogeneities of radar backscatter. We found that signatures of atmospheric phenomena may cover the major part of some radar images with variations of the radar signal intensity so high that it is impossible to identify NOS. Such a situation is presented in Figure 10d. Wind field variations caused by convective processes in the marine atmosphere produce prominent cellular structures in the radar image so that the NOS cannot be detected in this image.

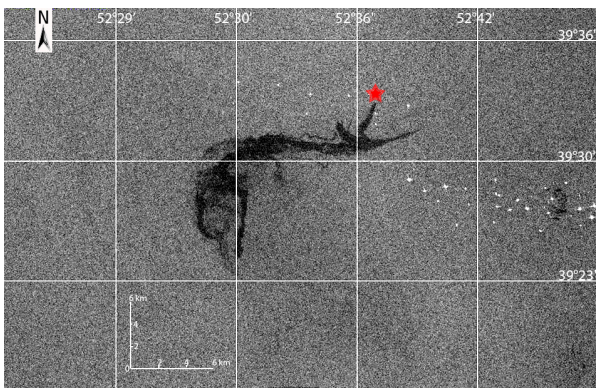

(a)

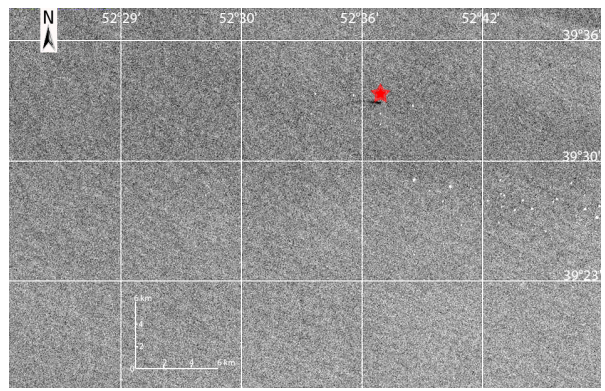

(b)

Figure 10. Cont. 




(c)

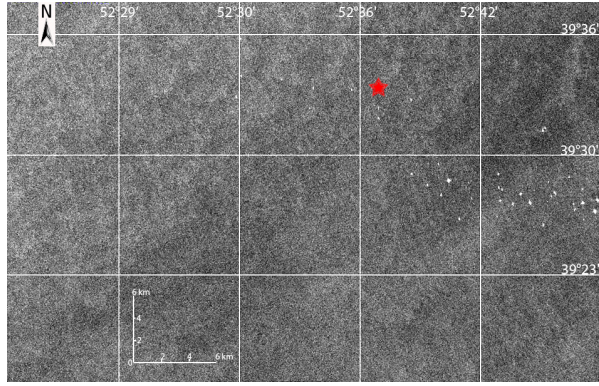

(d)

Figure 10. (a) A subset of Sentinel-1A SAR-C image of 12 September 2020, 14:29 UTC, taken at a moderate near-surface wind. A NOS with an area of about $50 \mathrm{sq} . \mathrm{km}$ is clearly seen; (b) a subset of Sentinel-1A SAR-C image of 18 September 2020, 02:36 UTC, taken at a high near-surface wind; (c) a subset of Sentinel-1A SAR-C image of 18 October 2020, 14:29 UTC, taken at a low near-surface wind; (d) a subset of Sentinel-1A SAR-C image of 23 November 2020, 14:29 UTC, taken in the presence of active convective processes in the sea-atmosphere boundary layer. The red star marks the location of the emission point at the sea surface.

It should be noted that the combined use of SAR and VIS data can increase NOS detectability, especially in the warm season.

Our study revealed another exciting problem that is beyond the scope of this article. It is unclear why NOS distinctly visible in SAR images cannot be detected in VIS data during the cold season. The solution to this problem is one of the goals of future research.

To extract the NOS from satellite images, we used a semi-manual algorithm that is adequate for the purposes of our research. However, when it comes to the development of automatic surveillance systems, deep learning techniques present a unique capability of detecting oil spills over large geographical areas with high accuracy.

Various methods of oil slick detection in satellite images based on deep learning algorithms have been developed and demonstrated the effectiveness of such an approach. Up to date, the majority of the algorithms have focused on SAR data [50-52]. Our study shows that introducing VIS data into oil spill monitoring can improve detectability. This is why algorithms developed for optical data are of particular interest, such as the recently proposed by Seydi et al. [53] based on multispectral data of Landsat-5 TM.

Oil spills in different areas might vary due to meteorological conditions and current and circulation systems. It should be stressed that deep learning techniques use training and validation datasets. Such datasets are collected for various areas of the World Ocean, including the North Sea [50], the Mexico Gulf [53], the Indonesian waters [51], and some others. The Caspian Sea is an oil pollution hotspot, and there is a long-overdue need to implement a satellite monitoring system of surface oil pollution. The constant presence on the surface of the Caspian Sea of many oil slicks, different in shape, size and source of origin, makes it an excellent test region for the construction of training and validation datasets and application of deep learning methods.

We hope that the results presented in this article will be useful to scientists developing deep learning approaches to oil spill detection. Here we show the limitations in the applicability of remote sensing to oil slick detection on the sea surface. These limitations vary depending on sensor type and are mainly caused by the natural conditions in the area of interest at the time of the survey: hydrometeorological conditions, state of the near-surface ocean-atmosphere layer, speed of the near-surface wind, etc. Regardless of how slicks are identified, manually by a qualified operator, or by a classification method, or using deep learning techniques, identifying oil slicks in a satellite image is possible only if their signatures are present in this image. 


\section{Conclusions}

This paper examines NOS from seabed natural hydrocarbon seeps as seen in satellite SAR and VIS images. Our research and obtained results provide new knowledge on the spatial and temporal variability of NOS in the Caspian Sea and the possibilities of their reliable detection using satellite VIS and SAR data.

Our two regions of interest in the Caspian Sea are located (i) east of Cape Sefid Rud (Iran) and (ii) west of Cheleken Peninsula (Turkmenistan).

Satellite SAR and VIS data taken over the regions of interest were examined for this study. All in all, 702 satellite images of the Caspian Sea taken over the Iranian waters, and 801 satellite images taken over the Turkmenian waters were analyzed. The satellite remote sensing data in different spectral ranges revealed persistent slick formations on the sea surface above hydrocarbon seeps on the seabed. The locations of two offshore seeps on the Iranian shelf near the Cape Sefid Rud and the seep on the Turkmenian shelf near the Cheliken peninsula were accurately estimated.

We found that NOS frequency and detectability in satellite images varies significantly and largely depends on sensor type and season, its seasonal variability being most pronounced in VIS data. The dependence of these parameters on the geographical region is also revealed. Further, we showed that a combined SAR and VIS data analysis can considerably improve NOS detectability, especially in the warm season.

We drew statistics on individual sizes of natural oil showings on the sea surface in two areas of interest. Based on these statistics, we can state that the release rates of the crude oil from the seabed to the surface are higher in the Turkmenian waters.

Maps are produced of sea surface pollution by NOS detected in satellite imagery taken over seepage sites, making it possible to assess the probability of oil contamination of various sea surface areas. High-risk areas of sea surface oil pollution and areas exposed to potential risks near seep sites are outlined. While the high risk of sea surface oil pollution by NOS is attributed to areas of $100 \mathrm{~km}^{2}$ and $200 \mathrm{~km}^{2}$, the sea surface areas potentially prone to oil pollution are assessed as $1200 \mathrm{~km}^{2}$ and $1500 \mathrm{~km}^{2}$ correspondingly, which is a significant threat to the ecology of the sea.

Author Contributions: Conceptualization, M.M.; Data curation, O.L.; Formal analysis, M.M.; Investigation, M.M. and O.L.; Methodology, M.M. and O.L.; Visualization, M.M.; Writing-original draft, M.M. All authors have read and agreed to the published version of the manuscript.

Funding: This research was funded by Russian Science Foundation, grant number 19-77-20060.

Institutional Review Board Statement: Not applicable.

Informed Consent Statement: Not applicable.

Data Availability Statement: SAR-C Sentinel 1A, 1B and MSI Sentinel-2A, 2B data are available after registration from https: / / scihub.copernicus.eu / (accessed on 17 January 2022); OLI Landsat-8 and TM Landsat-5 data are available after registration from https:/ / glovis.usgs.gov/ (accessed on 17 January 2022); ASAR Envisat data are available after registration from https: / / esar-ds.eo.esa.int/oads / access / (accessed on 17 January 2022).

Acknowledgments: Processing of satellite data was carried out using the See the Sea system of IKI-Monitoring Center for Collective Use.

Conflicts of Interest: The authors declare no conflict of interest.

\section{References}

1. Espedal, H.A.; Wahl, T. Satellite SAR oil spill detection using wind history information. Int. J. Remote Sens. 1999, 20, 49-65. [CrossRef]

2. Solberg, A.H.S.; Storvik, G.; Solberg, R.; Volden, E. Automatic detection of oil spills in ERS SAR images. IEEE Trans. Geosci. Remote Sens. 1999, 37, 1916-1924. [CrossRef]

3. Brekke, C.; Solberg, A. Oil spill detection by satellite remote sensing. Remote Sens. Environ. 2005, 95, 1-13. [CrossRef]

4. Topouzelis, K.N. Oil spill detection by SAR images: Dark formation detection, feature extraction and classification algorithms. Sensors 2008, 8, 6642-6659. [CrossRef] 
5. Nunziata, F.; Migliaccio, M.; Li, X. Sea oil slick observation using hybrid-polarity SAR architecture. IEEE J. Ocean. Eng. 2014, 40, 426-440. [CrossRef]

6. Migliaccio, M.; Nunziata, F.; Buonoa, A. SAR polarimetry for sea oil slick observation. Int. J. Remote Sens. 2015, 36, $3243-3273$. [CrossRef]

7. Alpers, W.; Holt, B.; Zeng, K. Oil spill detection by imaging radars: Challenges and pitfalls. Remote Sens. Environ. 2017, 201, 133-147. [CrossRef]

8. Kvenvolden, K.A.; Cooper, C.K. Natural seepage of crude oil into the marine environment. Geo-Mar. Lett. 2003, 23, 140-146. [CrossRef]

9. Selley, R.C.; Sonnenberg, S.A. Elements of Petroleum Geology, 3rd ed.; Elsevier: Amsterdam, The Netherlands, 2015 ; pp. 1-526. [CrossRef]

10. MacDonald, I.R.; Leifer, I.; Sassen, R.; Stine, P.; Mitchell, R.; Guinnasso, , N.L., Jr. Transfer of hydrocarbons from natural seeps to the water column and atmosphere. Geofluids 2002, 2, 95-107. [CrossRef]

11. Daneshgar, A.S.; Dukhovskoy, D.S.; Bourassa, M.; MacDonald, I.R. Hindcast modeling of oil slick persistence from natural seeps. Remote Sens. Environ. 2017, 189, 96-107. [CrossRef]

12. Fingas, M.; Brown, C. Review of oil spill remote sensing. Mar. Pollut. Bull. 2014, 83, 9-23. [CrossRef]

13. Espedal, H.A.; Johannessen, O.M.; Knulst, J. Satellite detection of natural films on the ocean surface. Geophys. Res. Lett. 1996, 23, 3151-3154. [CrossRef]

14. Jatiault, R.; Loncke, L.; Dhont, D.; Imbert, P.; Dubucq, D. Geophysical characterization of active thermogenic oil seeps in the salt province of the lower Congo basin part I: Detailed study of one oil-seeping site. Mar. Pet. Geol. 2019, 103, 753-772. [CrossRef]

15. Mitra, D.S.; Majumdar, T.J.; Ramakrishnan, R.; Dave, H.; Mazumder, S. Detection and monitoring of offshore oil seeps using ERS/ENVISAT SAR/ASAR data and seep-seismic studies in Krishna-Godavari offshore basin, India. Geocarto Int. 2013, 28, 404-419. [CrossRef]

16. Logan, G.; Jones, A.; Ryan, G.; Wettle, M.; Thankappan, M.; Grosjean, E.; Rollet, N.; Williams, J.K. A Review of Australian Offshore Natural Hydrocarbon Seepage Studies. Geosci. Aust. Rec. 2008, 17, 235.

17. Nunziata, F.; de Macedo, C.R.; Buono, A.; Velotto, D.; Migliaccio, M. On the analysis of a time series of X-band TerraSAR-X SAR imagery over oil seepages. Int. J. Remote Sens. 2018, 40, 3623-3646. [CrossRef]

18. MacDonald, I.R.; Guinasso, N.L.; Ackleson, S.G.; Amos, J.F.; Duckworth, R.; Sassen, R.; Brooks, J.M. Natural oil slicks in the Gulf of Mexico visible from space. J. Geophys. Res. 1993, 98, 16351-16364. [CrossRef]

19. MacDonald, I.R.; Reilly, J.; Best, S.E.; Venkataramaiah, R.; Sassen, R.; Guinasso, N.L.; Amos, J. Remote sensing inventory of active oil seeps and chemosynthetic communities in the Northern Gulf of Mexico. In Hydrocarbon Migration and Its Near-Surface Expression: AAPG Memoir; Schumacher, D., Abrams, M.A., Eds.; American Association of Petroleum Geologists: Tulsa, OK, USA, 1996; Volume 66, pp. 27-37. [CrossRef]

20. MacDonald, I.R. Natural oil spills. Sci. Am. 1998, 279, 56-61. [CrossRef]

21. De Beukelaer, S.M.; MacDonald, I.R.; Guinnasso, N.L.; Murray, J.A. Distinct side-scan sonar, RADARSAT SAR, and acoustic profiler signatures of gas and oil seeps on the Gulf of Mexico slope. Geo-Mar. Lett. 2003, 23, 177-186. [CrossRef]

22. MacDonald, I.R.; Bohrmann, G.; Escobar, E.; Abegg, F.; Blanchon, P.; Blinova, V.; Brückmann, W.; Drews, M.; Eisenhauer, A.; Han, X.; et al. Asphpalt volcanism and chemosynthetic life, Campeche Knolls, Gulf of Mexico. Science 2004, 304, 999-1002. [CrossRef] [PubMed]

23. MacDonald, I.R.; Garcia-Pineda, O.; Beet, A.; Daneshgar, A.S.; Feng, L.; Graettinger, G.; French-McCay, D.; Holmes, J.; Hu, C.; Huffer, F.; et al. Natural and unnatural oil slicks in the Gulf of Mexico. J. Geophys. Res. Oceans 2015, 120, 8364-8380. [CrossRef]

24. Li, X.; Li, C.; Yang, Z.; Pichel, W. SAR imaging of ocean surface oil seep trajectories induced by near inertial oscillation. Remote Sens. Environ. 2013, 130, 182-187. [CrossRef]

25. Hu, C.; Li, X.; Pichel, W.G.; Muller-Karger, F.E. Detection of natural oil slicks in the NW Gulf of Mexico using MODIS imagery Geophys. Res. Lett. 2009, 36, L01604. [CrossRef]

26. Hornafius, J.S.; Quigley, D.C.; Luyendyk, B. The world's most spectacular marine hydrocarbon seeps (Coal Oil Point, Santa Barbara Channel, California): Quantification of emissions. J. Geophys. Res. 1999, 104, 20703-20711. [CrossRef]

27. DiGiacomo, P.M.; Washburn, L.; Holt, B.; Jones, B.H. Coastal pollution hazards in southern California observed by SAR imagery: Stormwater plumes, wastewater plumes, and natural hydrocarbon seeps. Mar. Pollut. Bull. 2004, 49, 1013-1024. [CrossRef] [PubMed]

28. Leifer, I. A Synthesis Review of Emissions and Fates for the Coal Oil Point Marine Hydrocarbon Seep Field and California Marine Seepage. Geofluids 2019, 2019, 4724587. [CrossRef]

29. Wagner-Friedrichs, M. Seafloor Seepage in the Black Sea: Mud Volcanoes, Seeps and Diapiric Structures Imaged by Acoustic Methods. Ph.D. Thesis, University of Bremen, Bremen, Germany, 2007.

30. Lavrova, O.Y.; Mityagina, M.I. Satellite monitoring of oil slicks on the Black Sea surface. Izv. Atmos. Ocean. Phys. 2013, 49, 897-912. [CrossRef]

31. Körber, J.H.; Sahling, H.; Pape, T.; Ferreira, K.S.; McDonald, I.; Bohrmann, G. Natural oil seepage at Kobuleti Ridge, eastern Black Sea. Mar. Petrol. Geol. 2014, 50, 68-82. [CrossRef]

32. Evtushenko, N.V.; Ivanov, A.Y. Oil seeps in the southeastern Black Sea studied using satellite synthetic aperture radar images. Izv. Atmos. Ocean. Phys. 2013, 49, 913-918. [CrossRef] 
33. Lavrova, O.Y.; Mityagina, M.I. Natural Oil Slicks in the Southeastern Black Sea. In The Handbook of Environmental Chemistry; Springer: Berlin/Heidelberg, Germany, 2020. [CrossRef]

34. Bayramov, E.; Kada, M.; Buchroithner, M. Monitoring oil spill hotspots, contamination probability modelling and assessment of coastal impacts in the Caspian Sea using SENTINEL-1, LANDSAT-8, RADARSAT, ENVISAT and ERS satellite sensors. J. Oper. Oceanogr. 2018, 11, 27-43. [CrossRef]

35. Ivanov, A.Y.; Dostovalov, M.Y.; Sineva, A.A. Characterization of oil pollution around the Oil Rocks production site in the Caspian Sea using spaceborne polarimetric SAR imagery. Izv. Atmos. Ocean. Phys. 2012, 48, 1025-1037. [CrossRef]

36. Ivanov, A.Y.; Gerivani, H.; Evtushenko, N.V. Characterization of natural hydrocarbon seepage in the South Caspian Sea off Iran using satellite SAR and geological data. Mar. Georesour. Geotechnol. 2019, 38, 527-538. [CrossRef]

37. Mityagina, M.; Lavrova, O. Satellite Survey of Inner Seas: Oil Pollution in the Black and Caspian Seas. Remote Sens. 2016, 8, 875. [CrossRef]

38. Mityagina, M.I.; Lavrova, O.Y.; Kostianoy, A.G. Main pattern of the Caspian Sea surface oil pollution revealed by satellite data Ecol. Montenegrina 2019, 25, 91-105. [CrossRef]

39. Mityagina, M.I.; Lavrova, O.Y. Oil pollution hotspots on the Caspian Sea surface identified using satellite remote sensing. In SPIE Remote Sensing, Proceedings of the Remote Sensing of the Ocean, Sea Ice, Coastal Waters, and Large Water Regions 2020; SPIE-International Society for Optics and Photonics: Bellingham, WA, USA, 2020; Volume 11529, p. 115290L. [CrossRef]

40. Mammadov, R.M. Caspian Sea: Hydrometeorological Variability and Ecogeographical Problems; ELM: Baku, Azerbaijan, 2007; 436p.

41. Aliyev, I. Caspian Oil of Azerbaijan; Izvestiya: Moscow, Russia, 2003; pp. 1-712.

42. Lavrova, O.Y.; Mityagina, M.I.; Kostianoy, A.G. Online database "See The Sea” for the Caspian Sea. Ecol. Montenegrina 2019, 25, 79-89. [CrossRef]

43. Neteler, M.; Bowman, M.H.; Landa, M.; Metz, M. GRASS GIS: A multi-purpose open-source GIS. Environ. Model Softw. 2012, 31, 124-130. [CrossRef]

44. Jenkins, A.D.; Jacobs, S.J. Wave damping by a thin layer of viscous fluid. Phys. Fluids 1997, 9, 1256-1264. [CrossRef]

45. Mityagina, M.; Churumov, A. Radar backscattering at sea surface covered with oil films. In Global Developments in Environmental Earth Observation from Space; Millpress: Rotterdam, The Netherlands, 2006; pp. 783-790.

46. Jackson, C.R.; Alpers, W. The role of the critical angle in brightness reversals on sunglint images of the sea surface. J. Geophys. Res. Oceans 2010, 115, C09019. [CrossRef]

47. Gade, M.; Alpers, W.; Hühnerfuss, H.; Wismann, V.; Lange, P. On the reduction of the radar backscatter by oceanic surface films: Scatterometer measurements and their theoretical interpretation. Remote Sens. Environ. 1998, 66, 52-70. [CrossRef]

48. Gade, M.; Alpers, W.; Hühnerfuss, H.; Masuko, H.; Kobayashi, T. Imaging of biogenic and anthropogenic ocean surface films by the multifrequency/multipolarization SIR-C/X-SAR. J. Geophys. Res. Oceans 1998, 103, 18851-18866. [CrossRef]

49. Gade, M.; Alpers, W. Using ERS-2 SAR images for routine observation of marine pollution in European coastal waters. Sci. Total Environ. 1999, 237-238, 441-448. [CrossRef]

50. Song, D.; Zhen, Z.; Wang, B.; Li, X.; Gao, L.; Wang, N.; Tao Xie, T.; Zhang, T. A Novel Marine Oil Spillage Identification Scheme Based on Convolution Neural Network Feature Extraction From Fully Polarimetric SAR Imagery. IEEE Access 2020, 8 , 59801-59820. [CrossRef]

51. Gautama, B.G.; Longépé, N.; Fablet, R.; Mercier, G. Assimilative 2-D Lagrangian transport model for the estimation of oil leakage parameters from SAR images: Application to the Montara oil spill. IEEE J. Sel. Top. Appl. Earth Obs. Remote Sens. 2016, 9 , 4962-4969. [CrossRef]

52. Amri, E.; Courteille, H.; Benoit, A.; Philippe Bolon, P.; Dubucq, D.; Poulain, G.; Credoz, A. Deep learning based automatic detection of offshore oil slicks using SAR data and contextual information. In SPIE Remote Sensing, Proceedings of the Remote Sensing of the Ocean, Sea Ice, Coastal Waters, and Large Water Regions; SPIE-International Society for Optics and Photonics: Bellingham, WA, USA, 2021; Volume 1185707, pp. 1185707-1-1185707-8. [CrossRef]

53. Seydi, S.; Hasanlou, M.; Amani, M.; Huang, W. Oil Spill Detection Based on Multi-Scale Multi-Dimensional Residual CNN for Optical Remote Sensing Imagery. IEEE J. Sel. Top. Appl. Earth. Obs. Remote Sens. 2021, 14, 10941-10952. [CrossRef] 